Vol. 4, No. 1 | January - June 2020

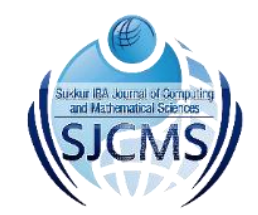

\title{
Average Index Modelling of Campus Safety and Walkability: Case Study of the University of Sindh
}

\author{
Irfan Ahmed Memon ${ }^{1}$, Saima Kalwar ${ }^{1}$, Noman Sahito ${ }^{1}$, Sabeen Qureshi ${ }^{1}$, Noman
}

Memon $^{1}$

\begin{abstract}
:
A pedestrian-friendly area encourages the inhabitants to experience the place enjoyably on foot. A pedestrian's sense of comfort is defined by the environmental qualities that encourage walking. The city's environmental qualities also make them better for walking, encouraging both physical and social activities. This Study focuses on safety and walkability in the University of Sindh. According to a survey done by researchers at the University of Sindh, the important issue at the university is lacking pedestrian facilities. Therefore, this study covers major facets of walkability. It is envisioned for policymakers and planners who want to improve the walking spaces for their communities with the best current information on pedestrian facilities. This research identified basic details about the specific walking plans and project creation. It includes trail preparation, roads, street lighting, street repairs, path and track repair, public protection, personal security, etc. This research explores the improvement of university walkways to accommodate pedestrians through the Average Index Model. Besides, the study presents recommendations on the issue of pedestrian safety. Also, discusses how the University of Sindh's road network aspects and addresses how campus roadway system could include sustainable transportation choices for inhabitants.
\end{abstract}

Keywords: Pedestrian safety; pedestrian walkability; average index model

\section{Introduction}

Universities around the world are committed to providing their students and staff with conducive living and learning environments, so campus manipulators' mobility is a problem that is faced by many major universities and needs to tackle as part of their environmental efforts on campuses. Campus walkability is a significant accessibility element of on-campus mobility. Travelers need access to a network of routes that are connected directly and easy to follow, connecting the hostel, open fields, faculties, public transit stops, and other amenities. Thus, it enhances their campus experience, focused on health, safety, accessibility, enjoyment, and learning $[1,2]$.

Walking is also correlated with other benefits, varying from air quality control, road congestion, and health problems such as reducing obesity. It is also encouraging neighborly interactions and a more comfortable and healthy way to live in an urban environment. There are enough justifications on the association between the built environment and walking [3, 4]. The key aim when measuring walkability on a university campus is to promote safe living, reduce congestion, and sustainable alternative

${ }^{1}$ Mehran University of Engineering \& Technology, Jamshoro, Sindh, Pakistan Corresponding Author: irfan.ahmed@ faculty.muet.edu.pk 
of mode choice. Walkability is the main component of sustainable alternative mode choice and offers societal advantages and contributions to public wellbeing, environmental prosperity, and preserving the climate. A pedestrian-friendly environment can decrease vehicle use and encourage walking [1].

The University of Sindh, the oldest and the largest university in Pakistan. The total number of students is almost 35000 in 2020. The total number of teachers is 800 and 65 Departments. There is insufficient space for walking due to that accidents are common inside the campus. Erstwhile, Sindh University student died after being hit by campus transport $[5,6]$. Meanwhile, there is unattractive roads, unsafe, and uncomfortable environment. On the other hand, people use to walk on the roads rather than pedestrians, it is because of a lack of awareness. Therefore, there is a need for the pedestrian in the University of Sindh.

Therefore, this study identified the existing condition of the campus for pedestrian facilities and to evaluating a walkability aspect i.e. its characteristics and potential.

\section{Literature Review}

\subsection{Walkability}

Walkability applies to the urban area that is comfortable with a variety of activities [7]. Walkability is the degree of accessibility and protection for pedestrians such as; lack of casual observations, gaps between pedestrians and automobiles as well as high-quality linked footpaths [8].

The walkability is the degree to which walking is readily accessible as a secure, linked, affordable and fine form of transportation. Walking can be a first-class mode of travel if the surroundings provide the quality of walking conditions, safety, remedy, and convenience [9].

\subsection{Connectivity and Accessibility}

Connectivity and accessibility are important courtesy to pedestrians [10]. Connectivity is about the easy movement from origins to destinations and it is the key element affecting the route assignment of pedestrians [11].

To encourage human beings to wander across the area, road networks need to be better linked with appropriate sidewalks to a specific holiday location. A well-planned road network has streets that are well connected to other mode choices. The streets also offer a variety of facilities and spaces, a correct fine of paths, sufficient walking distance, clear signs. The drawing of the road provides artistic pastime for the urban community. Both of these considerations are important for ease of walking [12].

Accessibility is an essential component of walkability. A community is nice because everyone can access public spaces. A regular citizen can be impaired if connectivity is not accessible. Simultaneously, either a user with a wheelchair, a blind person, or an elderly is not affected in an on-site situation. Street with a frontage of parking makes pedestrians difficult to get inside in any building or structures it forces pedestrians to get involved in the parking lot $[3,4]$.

\subsection{Safety of Walking}

Safety is one of the main factors for walkability. Safe pedestrian environments enable pedestrians to walk safely and reduces incident or crime concern experiences. In 2005, Southworth believed that the exceptional atmosphere of taking walks could affect pedestrian intensity [12]. Pedestrian complexity is needed to improve protection as the places expand to be extra translucent. The thing regarding pedestrian security and safety is correlated with vehicle activity and crossing visibility and protection. Good street network virtually defines better walkability for the pedestrian to create more comfortable and safer circumstance. 
Irfan Ahmed Memon (et al.), Average Index Modelling of Campus Safety and Walkability: Case Study of the University of Sindh (pp. 37 - 44)

\section{Methodology}

This research investigated key issues through various approaches and tools. The survey participants posed closed-ended questions concerning the following topics:

- walkability indicators (Sidewalk width, Sidewalk Maintenance, Streetscape, Shading Devices, etc.)

- Walking experience from their origin to the faculties based on a scale as the need for the indicators 5 (need) to 1 (no need) indifferent aspects: safety, security, comfort, convenience, and interestingness.

Conclusively, two major data collection methods were used to obtain knowledge from the identified field of research. These are discussed as follows:

\subsection{Primary Source}

In this regard, the researcher selected the Sindh University Jamshoro main campus as a case study. From the primary source, the data was collected through various techniques i.e. quantitative method detailed survey, questionnaire, personnel observation. Moreover, the quantitative method was used to get the detailed information regarding pedestrian problems faced by people of the study area.

\subsubsection{Questionnaire}

The requirement for analysis work has generated a need for an effective method of sample sizing to reflect a defined demographic condition [13]. A new approach called "small sample technique" published a formula for exploring a sample size by the research division of the National Education Association [13]. By this approach, it shows the connection between sample size and total population. It should be recalled that as the population grows the sample size will decline and stay constant.

A sample size of 384 was chosen in this survey out of the 33523 population. The questionnaire was completely close-ended and filled from respondents in the study area, i. e Sindh University Jamshoro. The survey questionnaire consisted of two separate sections. The first section focused on personal information from the respondents. The second part was about research data which is to be collected from the respondents about pedestrian facilities and their interest in the improvement of the pedestrian in the university. A self-administered questionnaire was filled from students from different departments of the university This primary data set helped the researcher to achieve the objectives of the study.

\subsubsection{Traffic and Pedestrian Count Survey}

Traffic count is a count of vehicular or pedestrian traffic. It is conducted along a particular path or intersection. In this survey, the researcher surveyed pedestrians and vehicular traffic from the three different locations of the University of Sindh Jamshoro. As there were different main points for traffic count that were selected such as; Main gate, Central library (Zero-point), Hostel road. The number of vehicles was collected on manual sheets from 7:30 am to 8:30 am and peak hours from 1:30 pm to 2:30 pm. Traffic, as well as pedestrian count, were done from all 3 points.

\section{Average Index Model}

The study applied the Average Index model developed by Abd Majid and McCaffer which provides means to verify the validity of a criterion by the respondents $[14,15]$. State the expectations of the students and the powerful physical-environmental factors. Data analysis was carried out through content analysis to assess the students' efficacy of cycling and walking physical-environmental variables and the person analysis on encouraging students to do walking and cycling.

Program processing tools were used for data analysis and IBM SPSS was supported as help applications for data interpretation and performance categorization. Levels of the significance of physical-environmental variables for motivating students to bike and 
Irfan Ahmed Memon (et al.), Average Index Modelling of Campus Safety and Walkability: Case Study of the University of Sindh (pp. 37 - 44)

walk were tabled dependent on the number of responses for every physical-environmental attribute.

The average index was calculated based on the frequency analyses to determine the ranking of each factor to be considered. The average index modeling is computed to determine the following:

$$
\text { Average Index }=\left(\sum \text { aixi }\right) /\left(\sum x i\right)
$$

Where, $\mathrm{a}=$ constant, weighing factor for $\mathrm{i}$, $(\mathrm{i}=1,2,3 \ldots \ldots . . \mathrm{n}), \mathrm{Xi}=$ frequency of respondent. The classifications of the rating scales are as follows to assess the degree of significance of the constructability concepts considered in this analysis:

Extremely effective $\quad 3.50 \leq I \leq 4.00$ or $87.5 \leq I \leq 100$

Very effective $\quad 2.50 \leq I \leq 3.50$ or $62.5 \leq I<87.5$

Moderately effective $1.50 \leq I \leq 2.50$ or $37.5 \leq I<62.5$

Ineffective

$0.50 \leq I \leq 1.50$ or $12.5 \leq I<37.5$

Extremely ineffective $0.00 \leq I \leq 0.50$ or $0.00 \leq I<12.5$

\section{Results and Discussion}

As researchers have analyzed the data by using appropriate techniques according to the nature of the study to get the most accurate and reliable results. So, researchers have used different techniques including traffic count surveys, for measuring the volume of current traffic as well as pedestrians. Descriptive analysis, for analyzing the data in SPSS frequency/percentage and creating graphs in excel while the average index model was also used as for analyzing the needs of different elements in terms of safety and walkability in the University of Sindh.

The traffic count survey is done in the different timing in a day for taking the average of the passing vehicles and pedestrians. In this survey researchers have selected three different points in the university of Sindh from these points vehicles and pedestrians were counted in peak hours from 7:30 am to 8:30 am and 1:30 pm to 2:30 pm for 3 days. Table
1 describes the traffic count survey on three said road locations at the university. The total number of vehicles from the main gate to different points in university from 7:30 AM to 8:30 AM per hour is 1852 .

Table 1. Peak hour traffic count from7:30 AM to 8:30 AM

\begin{tabular}{|l|l|l|c|}
\hline Date & Points & $\begin{array}{l}\text { Time } \\
\text { AM }\end{array}$ & $\begin{array}{c}\text { No. } \\
\text { Vehicles }\end{array}$ \\
\hline $3 / 9 / 2019$ & CL (Zero & $\begin{array}{l}7: 30 \text { to } \\
8: 30\end{array}$ & 504 \\
& Point) & $\begin{array}{l}7: 30 \text { to } \\
8: 30\end{array}$ & 1121 \\
\hline $4 / 9 / 2019$ & Main & \\
& Gate & $7: 30$ to & 227 \\
\hline $5 / 9 / 2019$ & Hostel & \\
& Road & 8: & 1852 \\
\hline \multicolumn{4}{|l|}{ Total } \\
\hline
\end{tabular}

Table 2 shows the traffic count survey on the above-highlighted points of the campus. The total number of vehicles from the main gate to different points in university from 1:30 PM to 2: 30 PM per hour is 1212.

Table 2. Peak hour traffic count from 1:30 PM to 2:30 PM

\begin{tabular}{|l|l|l|c|}
\hline Date & Points & $\begin{array}{l}\text { Time } \\
\text { PM }\end{array}$ & $\begin{array}{c}\text { No. } \\
\text { Vehicles }\end{array}$ \\
\hline $3 / 9 / 2019$ & CL (Zero & $\begin{array}{l}1: 30 \text { to } \\
2: 30\end{array}$ & 302 \\
& Point) & \\
\hline $4 / 9 / 2019$ & Main & $\begin{array}{l}1: 30 \text { to } \\
2: 30\end{array}$ & 720 \\
& Gate & $1: 30$ to & 190 \\
\hline $5 / 9 / 2019$ & Hostel & $2: 30$ & \\
& Road & 1212 \\
\hline \multicolumn{2}{|c|}{ Total } \\
\hline \multicolumn{2}{|c|}{}
\end{tabular}

Table 3 express the pedestrian count survey at a different point in the University of Sindh Jamshoro from 7:30 AM to 8:30 AM, so the number of pedestrians at the main gate University of Sindh was larger than the other selected points. 
Irfan Ahmed Memon (et al.), Average Index Modelling of Campus Safety and Walkability: Case Study of the University of Sindh

Table 3. Peak hour pedestrian count from 7:30 AM to 8:30 AM

\begin{tabular}{|c|l|l|c|}
\hline Date & Points & $\begin{array}{l}\text { Time } \\
\text { AM }\end{array}$ & $\begin{array}{c}\text { No. } \\
\text { Vehicles }\end{array}$ \\
\hline $18 / 9 / 2019$ & $\begin{array}{l}\text { CL } \\
\text { (Zero } \\
\text { Point) }\end{array}$ & $\begin{array}{l}7: 30 \text { to } \\
8: 30\end{array}$ & 523 \\
& $\begin{array}{l}\text { Main } \\
\text { Gate }\end{array}$ & $\begin{array}{l}7: 30 \text { to } \\
8: 30\end{array}$ & 776 \\
\hline $19 / 9 / 2019$ & $\begin{array}{l}7: 30 \text { to } \\
8: 30\end{array}$ & 223 \\
\hline $20 / 9 / 2019$ & $\begin{array}{l}\text { Hostel } \\
\text { Road }\end{array}$ & 1522 \\
\hline \multicolumn{3}{|l|}{} \\
\hline \multicolumn{2}{|l|}{ Total }
\end{tabular}

Table 4 represents the pedestrian count survey at a different point in the campus at afternoon peak hours from 1:30 PM to 2:30 PM, so the number of pedestrians at the central library the University of Sindh was greater than the other selected points.

Table 4. Peak hour traffic count from 1:30 PM to 2:30 PM

\begin{tabular}{|c|l|l|c|}
\hline Date & Points & $\begin{array}{l}\text { Time } \\
\text { PM }\end{array}$ & $\begin{array}{c}\text { No. } \\
\text { Vehicles }\end{array}$ \\
\hline $18 / 9 / 2019$ & CL & $\begin{array}{l}1: 30 \text { to } \\
2: 30\end{array}$ & 720 \\
& $\begin{array}{l}\text { Zero } \\
\text { Point) }\end{array}$ & $\begin{array}{l}1: 30 \text { to } \\
2: 30\end{array}$ & 320 \\
\hline $19 / 9 / 2019$ & $\begin{array}{l}\text { Main } \\
\text { Gate }\end{array}$ & $\begin{array}{l}1: 30 \text { to } \\
2: 30\end{array}$ & 89 \\
\hline $20 / 9 / 2019$ & $\begin{array}{l}\text { Hostel } \\
\text { Road }\end{array}$ & 1111 \\
\hline \multicolumn{4}{|l|}{} \\
\hline \multicolumn{2}{|l|}{ Total } & \\
\hline
\end{tabular}

The researcher has conducted a descriptive analysis of 384 responses by percentage and frequency, the result shows in the data tables and different graphs for understanding the overall scenario of responses for the improvement of pedestrians in the University of Sindh Jamshoro. The number of respondents was 384 , so $n=384$.

The average duration of walking per day, as $50.5 \%$ people walk one hour per day, $42.7 \%$ walk 2-3 hours per day, $22 \%$ people walk $4-5$ hours per day, and $4 \%$ people walk 6 or more than 6 hours per day. The result shows that most people walk one hour per day as shown in Figure 1.

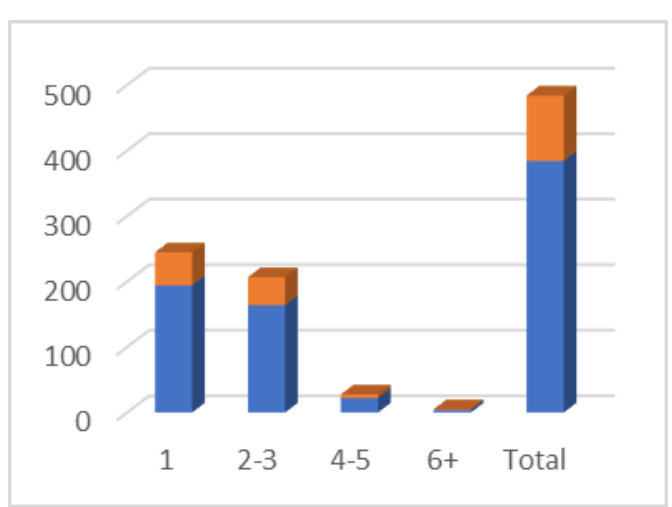

Fig. 1. Duration of walking per day

According to survey it was identified that different sort of barriers was faced by students while walking, according to $14.6 \%$ students too far distance is a barrier in walking, $40.9 \%$ roadside condition is the main barrier, $15.4 \%$ students harsh weather condition is the main barrier in walking and according to $29.2 \%$, unavailability of the footpath is the barrier. Most of the students consider roadside walk conditions as the main barrier in walking as discussed in Figure 2.

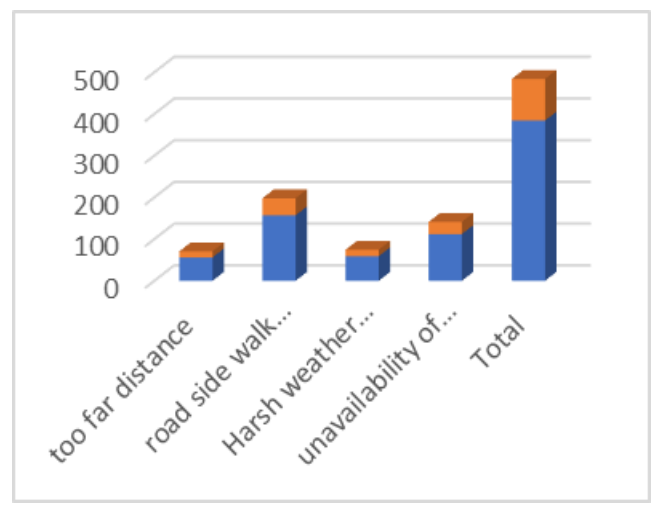

Fig. 2. Duration of walking per day

Likert scale 2.50 average total points mean there is satisfaction condition. If the value increases more than 2.50 it means, there is a need for that factor/there is a problem. If the 
Irfan Ahmed Memon (et al.), Average Index Modelling of Campus Safety and Walkability: Case Study of the University of Sindh

A.T.P (Average Total points) decrease less than 2.50 it means, there is no need for that factor/there is no problem.

Simultaneously, Average Point Index analysis in Table 5 shows the overall average satisfaction of university student about the factors which are mentioned below.

Furthermore, the findings of Average Index Analysis concluded that the most needed elements which scored as, Personal safety (fencing between roads and footpath) 4.09, Shade 4.25, Garbage cans/ Recycling 4.11and remaining elements. According to the survey, the majority walk around an hour per day. From the Analysis Students always walk with their friends on the pedestrian.

Table 5. Walkability elements average index modeling through Likert scale

\begin{tabular}{|l|c|c|c|c|c|c|c|}
\hline Likert scale & $\begin{array}{c}\text { Strongly } \\
\text { Agree }\end{array}$ & Agree & Neutral & Disagree & $\begin{array}{c}\text { Strongly } \\
\text { Disagree }\end{array}$ & TP/N & ATP \\
\hline Points & 5 & 4 & 3 & 2 & 1 & & \\
\hline Picnic tables/Benches & 122 & 150 & 54 & 30 & 28 & $1460 / / 384$ & 3.80 \\
\hline $\begin{array}{l}\text { Personal safety } \\
\text { (fencing between } \\
\text { roads and footpath) }\end{array}$ & 132 & 133 & 41 & 47 & 31 & $1573 / 384$ & 4.09 \\
\hline Shade & 114 & 165 & 51 & 31 & 23 & $1633 / 384$ & 4.25 \\
\hline $\begin{array}{l}\text { Garbage cans/ } \\
\text { Recycling }\end{array}$ & 130 & 130 & 63 & 33 & 29 & $1582 / 384$ & 4.11 \\
\hline Ramps and curbs & 122 & 160 & 67 & 20 & 15 & $1506 / 384$ & 3.92 \\
\hline Sign and road markers & 119 & 135 & 52 & 43 & 35 & $1412 / 384$ & 3.67 \\
\hline Gardens/flower beds & 110 & 98 & 76 & 60 & 40 & $1330 / 384$ & 3.46 \\
\hline Green space/ Nature / & 125 & 111 & 55 & 58 & 35 & $1385 / 384$ & 3.60 \\
Scenery & & & & & & & 143 \\
\hline Access to washroom & 136 & 132 & 46 & 43 & 27 & $1459 / 384$ & 3.799 \\
\hline Playgrounds & 90 & 74 & 131 & 40 & 49 & $1268 / 384$ & 3.30 \\
\hline Side walks & 145 & 115 & 70 & 33 & 21 & $1482 / 384$ & 3.85 \\
\hline
\end{tabular}

The survey result shows that roadside walking condition is the main barrier for cyclists and for pedestrian, absence of sidewalks in many areas of the University of Sindh forces the pedestrian to walk on the road which results in a pedestrian crash. Consequently, the direct observation existing sidewalks are uneven, unpaved and some are covered with tall grasses due to poor maintenance. Like the survey, the result shows that people depend on university buses as compare to pedestrians and people don't feel safe at peak hours. From the analysis, it has been evaluated that most of the residents live inside the campus i.e hostels. It was also found that major factor for road accident is poor enforcement by law and over speeding.

According to the survey sufficient number of signboards, speed breakers, road marking are not available, this item of aesthetic on 
roadways which help to direct the flow and direction of traffic need to be obeyed by road users, they could be in the form of solid white lines used to indicate parking, pedestrian, bicycle lanes and other features.

A survey result shows that pedestrian safety is the responsibility of university administration, so the university should take measures to enhance the walkways and footpaths, so people prefer walking instead of using an automobile.

\section{Conclusion}

The research here indicates the pedestrian's safety and walkability in the University of Sindh Jamshoro. The purpose of the research is to full fill the needs of the pedestrians and proposing the pedestrian in the university of Sindh Jamshoro. The data were collected from all students and staff of the university. Different techniques were used to analyze the data including the average index model, in the result that shows, there is a need for walkways, shades, ramps and curbs, garbage cans. A traffic count survey was done for knowing the volume of traffic as well as pedestrians at different points. Most of the pedestrians were facing problems while walking as they had to use roads for walking due to lack of walkways beside the roads on the campus. Descriptive analysis was also done, as a result, pedestrians were facing barriers while walking including, maintenance of walkways, unavailability of footpaths, too far distance, lack of shades on walkways, etc.

Policy and investments provide momentum to renovate public universities, encourage pedestrianization and allow people to enjoy better mobility and quality of life, so there must be valid and authentic policies for the improvement of the pedestrian at the University of Sindh Jamshoro.

The Administration of the University of Sindh Jamshoro must be involved in the development/improvement of the pedestrian under planning rules and pedestrian standards. Pedestrians' walkability and safety can be achieved by developing pedestrian services including sidewalks, shades, landscaping, Signboards, road marking, Ramps and curbs, Garbage cans, etc.

Traffic Rules must be imposed on vehicles that are violating the laws. Sindh university must possess multi/short, and long walkways between different departments for the encouragement of people's interest towards pedestrians.

Develop crosswalk marking in the university for providing easiness for pedestrians to cross the roads inside the university. Decrease crosswalk distance. In the case of pedestrian safety, there must be the installation of pedestrian lights and fencing on footpaths.

\section{REFERENCES}

[1] L. K. Keat, N. M. Yaacob, and N. R. Hashim, "Campus walkability in Malaysian public universities: A case study of Universiti Malaya," Planning Malaysia, vol. 14, no. 5, 2016.

[2] I. A. Memon, "Factors influencing travel behavior and mode choice among Universiti Teknologi Malaysia employees," Universiti Teknologi Malaysia, Faculty of Built Environment, 2010.

[3] S. Handy, L. Weston, and P. L. Mokhtarian, "Driving by choice or necessity?," Transportation Research part A: Policy and Practice, vol. 39, no. 2-3, pp. 183-203, 2005, DOI:

http://dx.doi.org/10.1016/j.tra.2004.09.002.

[4] S. Handy, X. Cao, and P. L. Mokhtarian, "Self-selection in the relationship between the built environment and walking: Empirical evidence from Northern California," Journal of the American Planning Association, vol. 72, no. 1, pp. 55-74, 2006.

[5] D. News. "Accredited universities, institutions' list issued." Dawn News. (accessed 11th July 2020).

[6] Z. Ali. "Student dies after being hit by Sindh University bus on campus." The Express Tribune.

https://tribune.com.pk/story/1328909/studentdies-hit-sindh-university-bus-campus (accessed 15th July 2020).

[7] H. Sung and S. Lee, "Residential built environment and walking activity: Empirical 
Irfan Ahmed Memon (et al.), Average Index Modelling of Campus Safety and Walkability: Case Study of the University of Sindh

evidence of Jane Jacobs' urban vitality," Transportation Research Part D: Transport and Environment, vol. 41, pp. 318-329, 2015.

[8] S. Shamsuddin, N. R. A. Hassan, and S. F. I. Bilyamin, "Walkable environment in increasing the liveability of a city," ProcediaSocial and Behavioral Sciences, vol. 50, pp. 167-178, 2012.

[9] T. Litman, "Online TDM Encyclopedia," in Online TDM Encyclopedia, ed. Victoria, BC, Canada: Victoria Transport Policy Institute, 2014.

[10] J. Rotmeyer, "Can elevated pedestrian walkways be sustainable," $e$ SustainableCityIV:

UrbanRegenerationandSustainability, pp. 293-302, 2006.

[11] S. T. D. E. M. Kumar, "Review Paper On Study of Pedestrian Flow on Grade Separated Crossing," 2014.
[12] M. Southworth, "Designing the walkable city," Journal of urban planning and development, vol. 131, no. 4, pp. 246-257, 2005.

[13] V. R. Krejcie and W. D. Morgan, "Determining sample size for research activities," Education and Psychological Measurement, vol. 30, pp. 607-610, 1970.

[14] M. Z. Abd Majid, Y. Bigah, A. Keyvanfar, A. Shafaghat, J. Mirza, and H. Kamyab, "Green Highway Development Features to Control Stormwater Runoff Pollution," Journal of Environmental Treatment Techniques, vol. 4, no. 4, pp. 173-175, 2015.

[15] M. A. Majid and R. McCaffer, "Assessment of work performance of maintenance contractors in Saudi Arabia. Discussion," Journal of Management in Engineering, vol. 13, no. 5, 1997. 